\title{
Desain Virtual Private Network (VPN) Berbasis Open Shortest Path First (OSPF)
}

\section{Hari Antoni Musril}

Program Studi Pendidikan Teknik Informatika dan Komputer Institut Agama Islam Negeri (IAIN) Bukittinggi, Kampus II IAIN Bukittinggi Jl. Gurun Aur Kubang Putih Kab. Agam, 26181, Sumatera Barat, Indonesia

\begin{tabular}{l} 
KEYWORDS \\
\hline VPN, OSPF, AAA server, router \\
CORRESPONDENCE \\
\hline Phone: +628126769772 \\
E-mail: kum ayik@yahoo.co.id
\end{tabular}

\section{PENDAHULUAN}

Jaringan komputer adalah himpunan "interkoneksi" antara dua komputer autonomous atau lebih yang terhubung dengan media transmisi kabel atau tanpa kabel [1]. Jaringan komputer mampu menghubungkan berbagai perangkat (device) baik yang diam (static) maupun yang bergerak (mobile) seperti smartphone. Salah satu perkembanagan jaringan komputer adalah teknologi internet, yang mendukung proses komunikasi dan transmisi data secara real time. Sehingga dengan internet hilanglah pembatas informasi dari segi ruang dan waktu. Internet sebagai jaringan publik dapat memberikan akses informasi dengan cepat dan mudah, sehingga setiap user dimanapun berada dan kapanpun waktunya dapat mengakses informasi baik milik pribadi, swasta, maupun pemerintah. Kemudahan tersebut harus diikuti dengan kemampuan untuk tetap menjaga keamanan informasi. Akses dalam sebuah jaringan komputer harus diawasi dan dibatasi [2].

VPN adalah sebuah teknologi komunikasi yang memungkinkan dapat terkoneksi ke jaringan publik dan menggunakannya untuk dapat bergabung dengan jaringan lokal [3]. Koneksi VPN dalam bentuk virtual (maya) dan bersifat private (rahasia), sehingga hanya user tertentu saja yang bisa mengaksesnya. VPN sangat dibutuhkan bagi suatu organisasi baik swasta (organisasai bisnis) maupun pemerintah yang memiliki unit dan cakupan wilayah kerja yang luas serta jumlah user yang banyak. User yang terhubung ke dalam jaringan VPN perlu akun dan sandi untuk login.

VPN diaplikasikan pada jaringan yang memiliki banyak router. Komunikasinya diatur oleh protokol routing. Routing adalah proses memilih lintasan yang akan ditempuh oleh sebuah paket data pada suatu jaringan komputer [4]. [5] OSPF adalah suatu protokol routing Link State (LS) yang bersifat terbuka atau didukung berbagai perangkat jaringan. OSPF dapat digunakan untuk menentukan jalur terbaik dalam pengiriman paket data di dalam jaringan skala besar.

Penelitian ini membuat jaringan VPN yang berjalan dalam protokol routing OSPF. Skema jaringan yang digunakan mengacu pada prototipe jaringan di area kampus yang memiliki dua buah lokasi berbeda. Perancangan dan konfigurasi memanfaatkan software Cisco Packet Tracer. Hasil prototipe ini bisa diterapkan dalam kondisi sebenarnya. 


\section{LANDASAN TEORI}

\section{Virtual Private Network (VPN)}

Menurut Internet Engineering Task Force (IETF) [6], VPN merupakan suatu bentuk private internet yang melalui public network (internet), dengan menekankan pada keamanan data dan akses global melalui internet. Prosedur enkripsi dilakukan terhadap data yang melalui VPN, sehingga keamanannya terjamin.

Prinsip Kerja VPN [7] :

- Komponen utamanya adalah VPN server.

- VPN Client akan mengirim pesan ke server VPN.

- Untuk proses login, VPN server memeriksa akun client.

- Komputer client dapat digunakan mengakses berbagai resource di VPN server.

Jenis VPN berdasarkan aksesnya yaitu [8] :

- Remote Access,

- dan Site to Site.

Manfaat jaringan VPN yaitu [7] :

- Untuk remote access,

- dan Menghemat keuangan.

\section{AAA Server}

Protokol AAA (Authentication, Authorization, Accounting) sebagai pengatur komunikasi antara client dengan domain yang sama, maupun antar client dengan domain yang berbeda [9]. Autentikasi merupakan tahapan mengenali siapa yang akan login. Otorisasi mengizinkan pengguna mengakses sumber daya sistem. Accounting merupakan proses pencatatan seluruh sumber daya yang digunakan dan besaran biayanya [10].

\section{Open Shortest Path First (OSPF)}

OSPF bekerja dengan landasan perutean hierarkis dengan membagi beberapa tingkatan jaringan. Tingkatan itu diaplikasikan dengan sistem pengelompokan area. Dengan menggunakan konsep perutean hierarki ini sistem penyebaran informasi dalam protokol OSPF menjadi lebih teratur dan tersegmentasi, sehingga tidak menyebar secara sembarangan [5].

\section{METODE PENELITIAN}

Pada tulisan ini metode penelitian yang digunakan adalah sebagai berikut :

1. Analisis. Berupa kegiatan kajian literatur. Literatur bersumber dari buku, jurnal ilmiah, dan penelitian yang membahas mengenai Virtual Provate Network (VPN) dan Open Shortest Path First (OSPF).

2. Desain. Di sini dilakukan proses perancangan topologi. Merancang jarinan fisik dan logika.

3. Pengembangan. Tahapan untuk konfigurasi prototipe. Alat yang diatur sesuai dengan topologi, antara lain router, PC, dan server.

4. Pengujian. Setelah prototipe jaringan selesai dikembangkan, setiap device dilakukan pengujian konektivitasnya dan pengujian VPN.

\section{HASIL DAN PEMBAHASAN}

\section{Skema Jaringan}

Skema jaringan pada desain Virtual Private Network (VPN) berbasis Open Shortest Path First (OSPF) seperti gambar berikut.

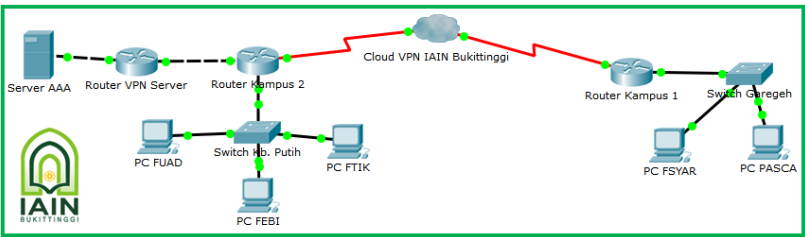

Figure 1. Skema jaringan untuk penelitian

Pengaturan OSPF dilakukan pada router VPN server, router Kampus 1, dan router kampus 2. Server AAA merupakan server yang digunakan untuk mengakses jaringan VPN. Cloud VPN IAIN Bukittinggi menjadi penghubung jaringan antara Kampus 1 dan Kampus 2. Tabel berikut ini adalah informasi mengenai alamat pada port aktif di masing-masing router.

Table 1. Konfigurasi Alamat Router

\begin{tabular}{|c|c|c|c|}
\hline Router & Port : IP & Address / Prefix & Clock Rate \\
\hline \multirow{2}{*}{ VPN Server } & $\mathrm{Fa} 0 / 0$ & $: 7.6 .4 .2 / 24$ & - \\
\hline & $\mathrm{Fa} 0 / 1$ & : 184.75.66.1/24 & - \\
\hline \multirow{3}{*}{ Kampus I } & $\mathrm{Fa} 0 / 0$ & $: 10.7 .6 .1 / 24$ & - \\
\hline & $\mathrm{Se} 3 / 0$ & $:-$ & 56000 \\
\hline & $\mathrm{Se} 3 / 0.101$ & : $35.18 .40 .1 / 24$ & - \\
\hline \multirow{3}{*}{ Kampus II } & $\mathrm{Fa} 1 / 0$ & $: 192.168 .1 .1 / 24$ & - \\
\hline & $\mathrm{Fa} 0 / 0$ & : 7.6.4.1/24 & - \\
\hline & $\mathrm{Se} 2 / 0$ & : 35.18.40.2/24 & 56000 \\
\hline
\end{tabular}

\section{Konfigurasi Router}

Pengaturan pada masing-masing router dilakukan melalui jendela CLI. Berikut ini merupakan konfigurasi di setiap router.

1. Konfigurasi di Router VPN Server : Konfigurasinya seperti berikut :

Router>enable

Router\#configure terminal

Router(config)\#hostname Router-VPN_Server

Router-VPN_Server(config)\#aaa new-model

Router-VPN_Server(config)\#aaa authentication login

VPNAUTH group radius local

Router-VPN_Server(config)\#aaa authorization network VPNAUTH local

Router-VPN_Server(config)\#crypto isakmp policy 10

Router-VPN_Server(config-isakmp)\#encr aes 256

Router-VPN_Server(config-isakmp)\#authentication pre-

share

Router-VPN_Server(config-isakmp)\#group 2

Router-VPN_Server(config-isakmp)\#exit

Router-VPN_Server(config)\#crypto isakmp client configuration group myciscogroup

Router-VPN_Server(config-isakmp-group)\#key

myciscogroup

Router-VPN_Server(config-isakmp-group)\#pool

VPNCLIENTS

Router-VPN_Server(config-isakmp-group)\#netmask 255.255.255.0

Router-VPN_Server(config-isakmp-group)\#exit 
Router-VPN_Server(config)\#crypto ipsec transform-set 6 esp-3des esp-sha-hmac

Router-VPN_Server(config)\#crypto dynamic-map mymap 10 Router-VPN_Server(config-crypto-map)\#set transform-set 6 Router-VPN_Server(config-crypto-map)\#reverse-route Router-VPN_Server(config-crypto-map)\#exit

Router-VPN_Server(config)\#crypto map mymap client authentication list VPNAUTH

Router-VPN_Server(config)\#crypto map mymap isakmp authorization list VPNAUTH

Router-VPN_Server(config)\#crypto map mymap client configuration address respond

Router-VPN_Server(config)\#crypto map mymap 10 ipsecisakmp dynamic mymap

Router-VPN_Server(config)\#ip ssh version 1 Router-VPN_Server(config)\#spanning-tree mode pvst

Router-VPN_Server(config)\#interface FastEthernet0/0 Router-VPN_Server(config-if)\#ip address 7.6.4.2 255.255.255.0

Router-VPN_Server(config-if)\#crypto map mymap Router-VPN_Server(config-if)\#no shutdown Router-VPN_Server(config-if)\#ip local pool VPNCLIENTS 201.1.100.100 201.1.100.150

Router-VPN_Server(config-if)\#exit

Router-VPN_Server(config)\#interface FastEthernet0/1 Router-VPN_Server(config-if)\#ip address 184.75.66.1 255.255.255.0

Router-VPN_Server(config-if)\#no shutdown

Router-VPN_Server(config-if)\#exit

Router-VPN_Server(config)\#ip route 201.1.100.0 255.255.255.0 7.6.4.1

Router-VPN_Server(config)\#radius-server host 184.75.66.100 auth-port 1645 key myciscovpn

Router-VPN_Server(config)\#router ospf 1

Router-VPN Server(config-router)\#network 7.6.4.0

0.0.0.255 area 0

Router-VPN_Server(config-router)\#network 184.75.66.0

0.0.0.255 area 0

Router-VPN_Server(config-router)\#exit

Router-VPN_Server(config)\#exit

Router-VPN_Server\#write memory

2. Konfigurasi di Router Kampus 1 : Pada router Kampus 1 konfigurasinya seperti berikut ini :

Router >enable

Router\#configure terminal

Router(config)\#hostname Router-KAMPUS_I

Router-KAMPUS_1(config)\#ip ssh version 1

Router-KAMPUS_1(config)\#spanning-tree mode pvst

Router-KAMPUS_1(config)\#interface FastEthernet0/0

Router-KAMPUS_1(config-if)\#ip address 10.7.6.1

255.255.255.0

Router-KAMPUS_1(config-if)\#no shutdown

Router-KAMPUS_1(config-if)\#exit

Router-KAMPUS_1(config)\#interface se $3 / 0$

Router-KAMPUS_1(config-if)\#encapsulation frame-relay ietf

Router-KAMPUS_1(config-if)\#frame-relay LMI-type ansi

Router-KAMPUS_1(config-if)\#clock rate 56000

Router-KAMPUS_1(config-if)\#no shutdown

Router-KAMPUS_1(config-if)\#exit
Router-KAMPUS_1(config)\#interface se3/0.101 point-topoint

Router-KAMPUS_1(config-subif)\#ip address 35.18.40.1 255.255.255.0

Router-KAMPUS_1(config-subif)\#frame-relay interface-dlci 101

Router-KAMPUS_1(config-subif)\#ip ospf network broadcast Router-KAMPUS_1(config-subif)\#no shutdown

Router-KAMPUS_1(config-subif)\#exit

Router-KAMPUS_1(config)\#router ospf 1

Router-KAMPUS_1(config-router)\#network 35.18.40.0

0.0.0.255 area 0

Router-KAMPUS_1(config-router)\#network 10.7.6.0

O.0.0.255 area 0

Router-KAMPUS_1(config-subif)\#exit

1) Konfigurasi di Router Kampus 2 : Pada router Kampus 2 konfigurasinya seperti berikut ini :

Router>enable

Router\#configure terminal

Router(config)\#hostname Router-KAMPUS_2

Router-KAMPUS_2(config)\#ip ssh version 1

Router-KAMPUS_2(config)\#spanning-tree mode pvst

Router-KAMPUS_2(config)\#interface FastEthernet1/0

Router-KAMPUS_2(config-if)\#ip address 192.168.1.1

255.255.255.0

Router-KAMPUS_2(config-if)\#no shutdown

Router-KAMPUS_2(config-if)\#exit

Router-KAMPUS_2(config)\#interface FastEthernet0/0

Router-KAMPUS_2(config-if)\#ip address 7.6.4.1 255.255.255.0

Router-KAMPUS_2(config-if)\#no shutdown

Router-KAMPUS_2(config-if)\#exit

Router-KAMPUS_2(config)\#interface se $2 / 0$

Router-KAMPUS_2(config-if)\#encapsulation frame-relay ietf

Router-KAMPUS_2(config-if)\#frame-relay LMI-type ansi

Router-KAMPUS 2(config-if)\#clock rate 56000

Router-KAMPUS_2(config-if)\#no shutdown

Router-KAMPUS_2(config-if)\#exit

Router-KAMPUS_2(config)\#interface se $2 / 0$ point-to-point Router-KAMPUS_2(config-subif)\#ip address 35.18.40.2 255.255.255.0

Router-KAMPUS_2(config-subif)\#frame-relay interface-dlci 101

Router-KAMPUS_2(config-subif)\#ip ospf network broadcast Router-KAMPUS_2(config-subif)\#no shutdown

Router-KAMPUS_2(config-subif)\#exit

Router-KAMPUS_2(config)\#router ospf 1

Router-KAMPUS_2(config-router)\#network

O.0.0.255 area 0

Router-KAMPUS_2(config-router)\#network 0.0.0.255 area 0

Router-KAMPUS_2(config-router)\#network 0.0.0.255 area 0

Router-KAMPUS_2(config-subif)\#exit

\section{Pengaturan Cloud VPN}

Port Se1 pada cloud VPN IAIN Bukittinggi dihubungkan ke router Kampus 1, dan port $\mathrm{Se} 0$ nya dihubungkan ke router Kampus 2. Setelah itu dilakukan konfigurasi perangkat frame relay pada cloud VPN IAIN Bukittinggi tersebut. Seperti gambar berikut ini. 


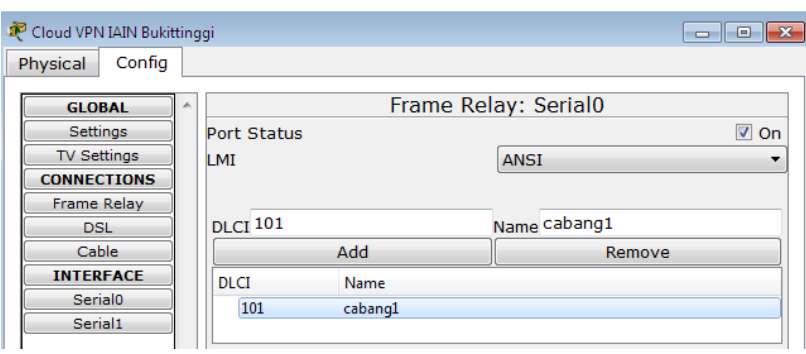

Figure 2. Konfigurasi serial0 di cloud VPN IAIN Bukittinggi

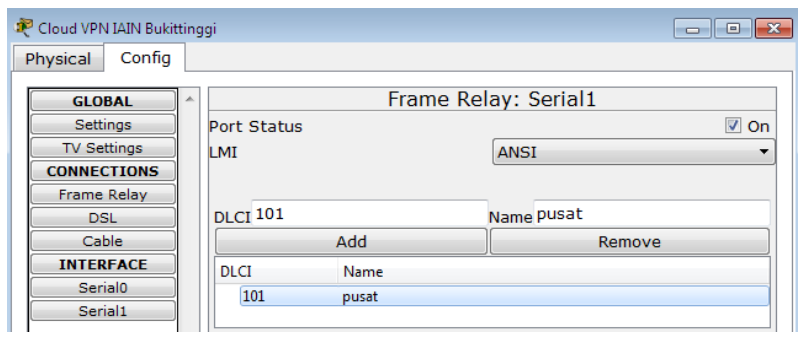

Figure 3. Konfigurasi serial1 di cloud VPN IAIN Bukittinggi

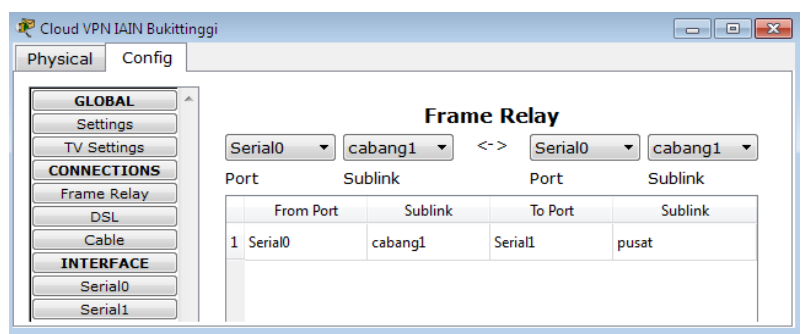

Figure 4. Konfigurasi frame relay di cloud VPN IAIN Bukittinggi

\section{Konfigurasi Server AAA}

Tahapan berikutnya adalah pengaturan pada server AAA. Server AAA akan melakukan proses autentikasi, otorisasi, dan akunting. AAA akan mengatur akses ke komputer dengan memeriksa user yang ingin tersambung. Berikut ini konfigurasi pada server AAA.

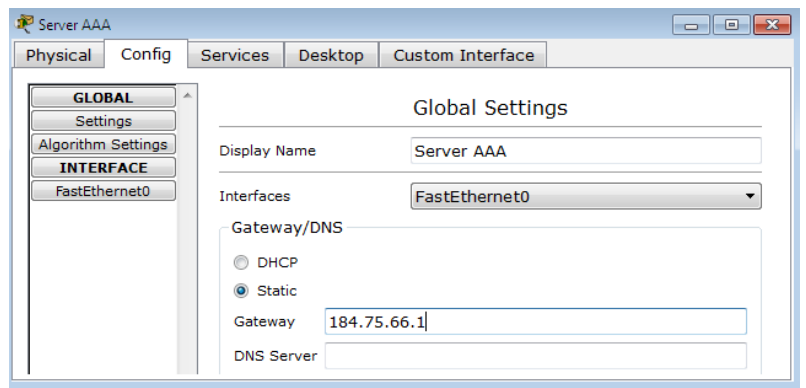

Figure 5. Konfigurasi display name dan IP address server AAA

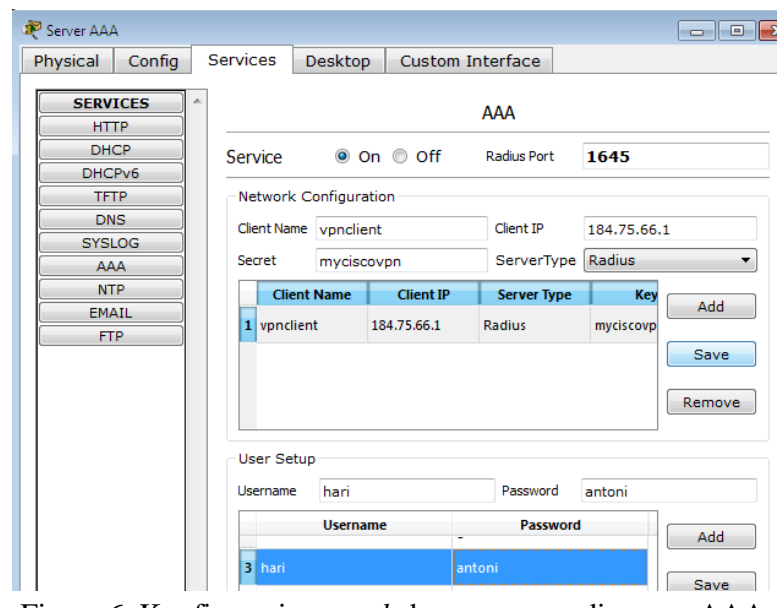

Figure 6. Konfigurasi network dan username di server AAA

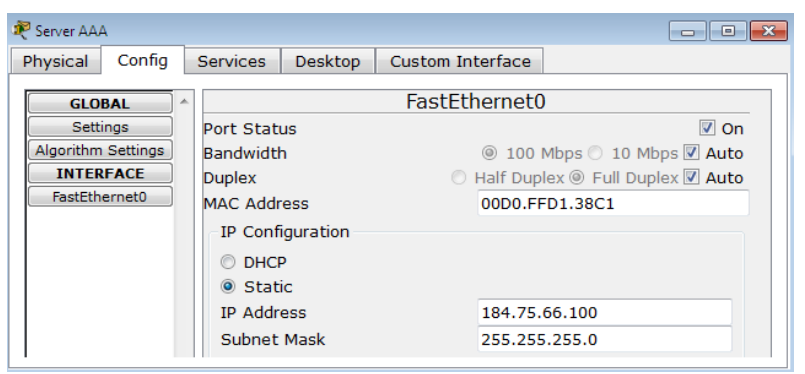

Figure 7. Konfigurasi alamat IP server AAA

\section{Koneksi ke VPN Server}

Setelah selesai melakukan semua konfigurasi, berikutnya adalah tahapan untuk menghubungkan komputer client ke jaringan VPN yang bekerja dalam routing OSPF. Gambar berikut ini merupakan tahapan koneksi pc FSYAR ke jaringan VPN.

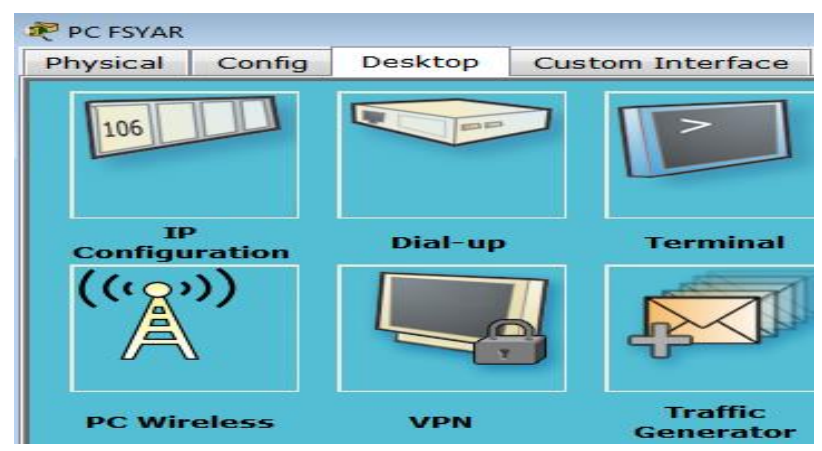

Figure 8. Proses awal koneksi VPN pada PC FSYAR

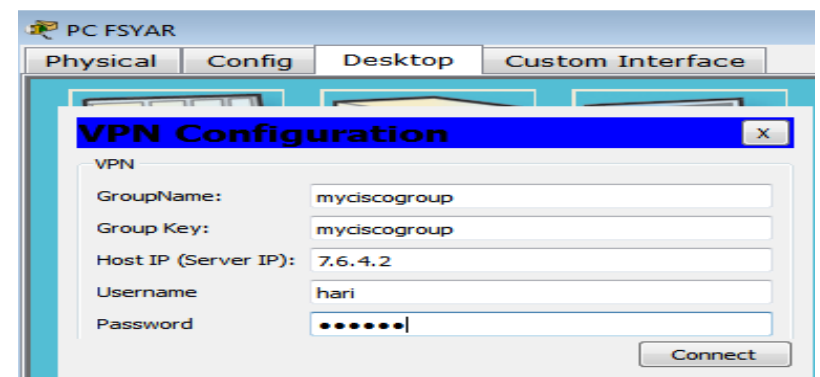

Figure 9. Proses login VPN ke server AAA dari PC FSYAR 


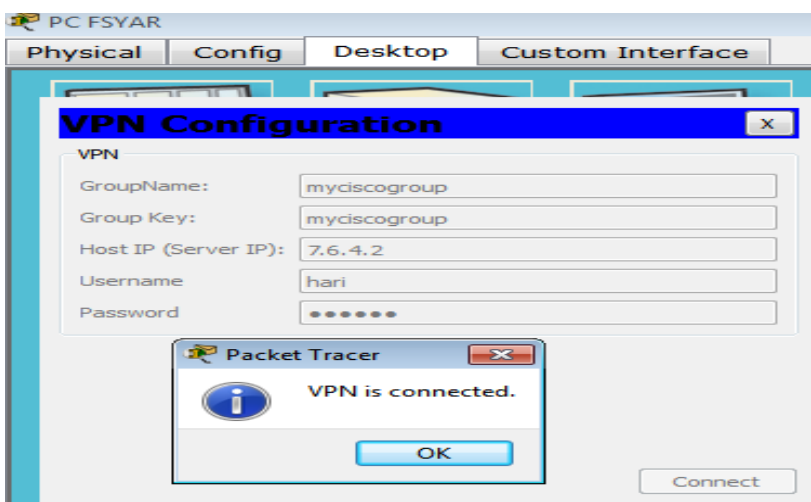

Figure 10. Proses login ke VPN berhasil

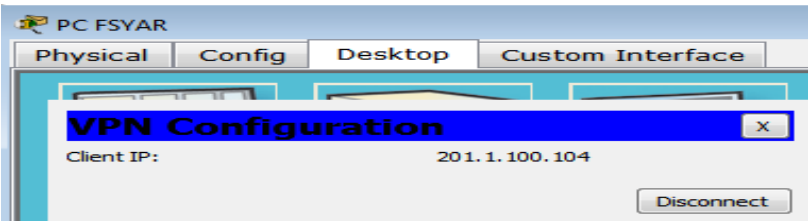

Figure 11. Alamat PC FSYAR pada saat login ke VPN

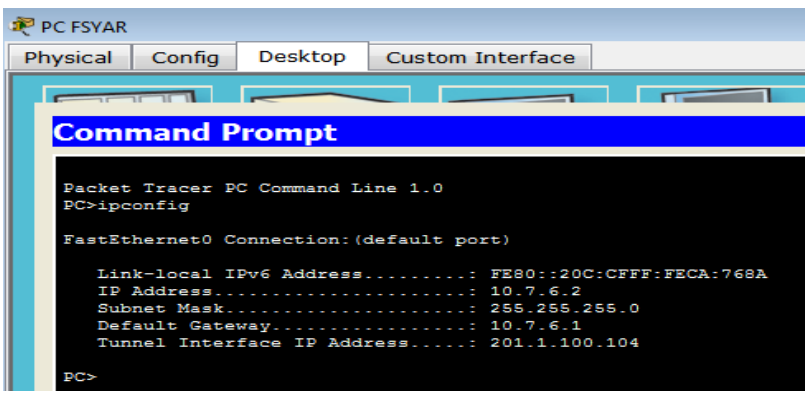

Figure 12. Informasi alamat IP pada PC FSYAR

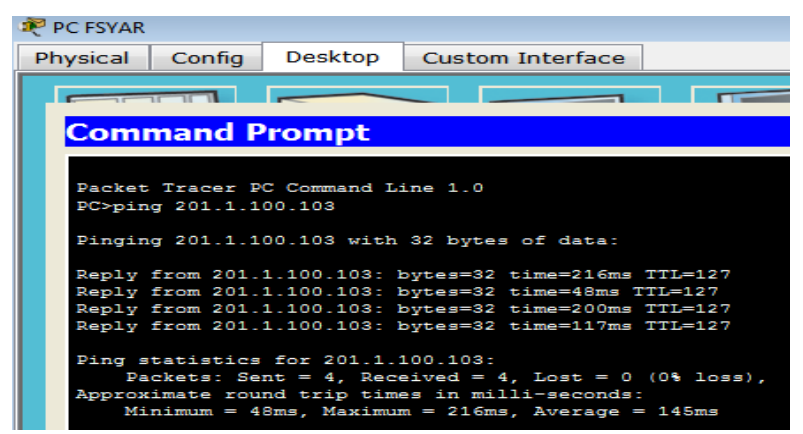

Figure 13. Uji koneksi ke komputer lain dalam jaringan VPN

\section{Hasil Simulasi}

Hasil desain VPN berbasis OSPF ini antara lain adalah :

1. Tabel Routing: diketahui dengan menulis perintah show ip route ospf pada setiap router. Berikut ini adalah hasilnya pada router kampus 2.

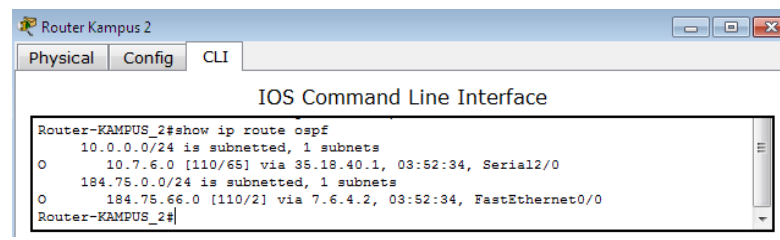

Figure 14. Tabel routing OSPF di router kampus 2
2. Tabel Neighbor: memuat informasi router neighbor. Gambar di bawah ini adalah tabel neighbor protokol OSPF di Kampus 2.

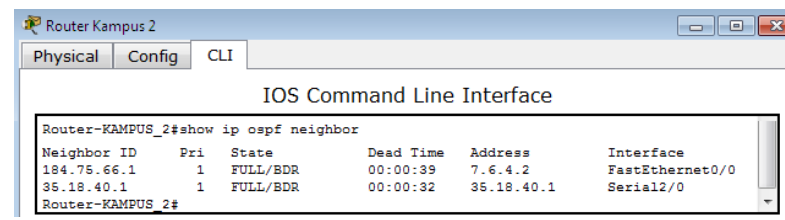

Figure 15. Tabel neighbor di router kampus 2

3. Database Routing : Untuk melihat database routing OSPF pada router menggunakan perintah show ip ospf database. Router kampus 2 memiliki database routing seperti berikut.

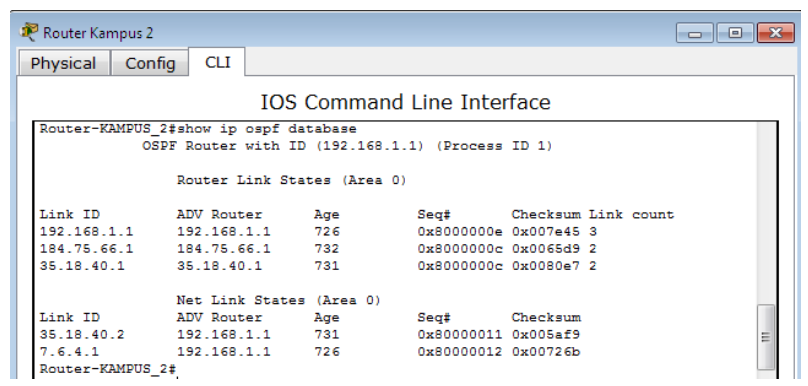

Figure 16. Database Routing OSPF di Router Kampus 2

4. Pengaturan IP Protocol : Untuk melihat pengaturan IP protokol dengan menggunakan perintah do show ip protocol. Gambar 17 di bawah adalah IP protokol di router Kampus 2.

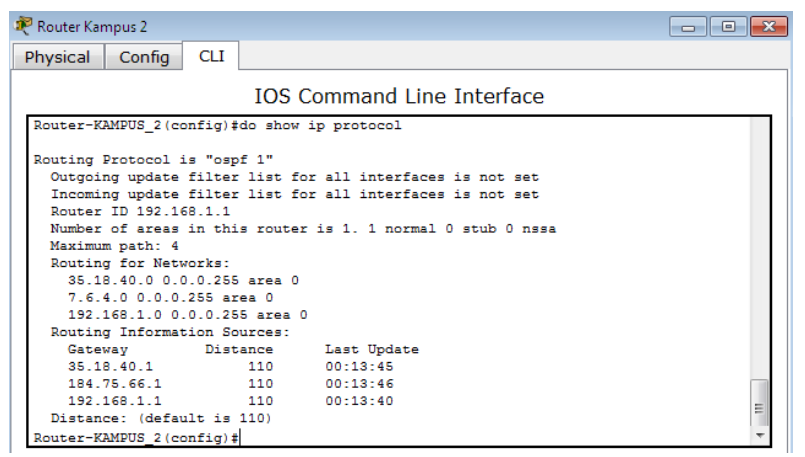

Figure 17. IP Protocol di Router Kampus 2

5. Koneksi ke VPN : Koneksi ke VPN dilakukan oleh PC user dengan mengambil menu VPN (lihat gambar 8). Kemudian input data group name, group key, server IP, username, dan password seperti terlihat pada gambar 9. Apabila ada data yang salah maka PC user tidak akan bisa untuk masuk ke VPN. gambar 10 merupakan PC user yang berhasil masuk ke VPN. Setelah PC user terhubung ke VPN maka PC tersebut akan mendapatkan tunnel interface IP address seperti nampak pada gambar 12. Setelah sebuah PC terhubung ke VPN maka PC tersebut dapat melakukan komunikasi dengan PC lain yang juga sudah terhubung ke VPN, seperti terlihat pada gambar 13. PC yang sedang terhubung dalam jaringan VPN tidak akan bisa mengakses alamat fisik dari PC lain.

\section{KESIMPULAN}

Kesimpulan yang dapat diambil adalah sebagai berikut : 
1. VPN dapat membuat akses data dan informasi ke jaringan menjadi lebih aman karena adanya mekanisme tunnel VPN yang melakukan enkapsulasi dan enkripsi terhadap data dalam jaringan.

2. Adanya username dan password user pada saat login ke VPN akan memudahkan proses monitoring terhadap user.

3. Pemanfaatan jaringan publik (internet) untuk menerapkan VPN dapat menghemat anggaran, karena tidak dibutuhkan infrastruktur tambahan untuk implementasinya.

4. Secara keseluruhan jaringan VPN yang berjalan dalam routing OSPF mampu bekerja dengan baik, dimana terdapat beberapa network yang berbeda namun dapat saling terhubung dalam jaringan private.

5. Routing OSPF dapat menghubungkan semua perangkat dalam skema jaringan yang dirancang baik dalam kondisi sebenarnya maupun dalam kondisi virtual (maya).

\section{REFERENSI}

[1] H. A. Musril, "Simulasi Interkoneksi Antara Autonomous System (AS) Menggunakan Border Gateway Protocol (BGP)," Jurnal Nasional Informatika dan Teknologi Jaringan (InfoTekJar), vol. 2, no. 1, pp. 1-9, 2017.

[2] H. A. Musril, "Extended Access List untuk Mengendalikan Trafik Jaringan," Jurnal Edukasi dan Penelitian Informatika (JEPIN), vol. 2, no. 2, pp. 129-135, 2016.

[3] P. Oktivasari, and A. B. Utomo, "Analisa Virtual Private Network Menggunakan OpenVPN dan Point To Point Tunneling Protocol," Jurnal Penelitian Komunikasi dan Opini Publik, vol. 20, no. 2, pp. 185-202, 2016.

[4] H. A. Musril, "Simulasi Interkoneksi Antara Autonomous System (AS) Menggunakan Border Gateway Protocol (BGP)" Jurnal Nasional Informatika dan Teknologi Jaringan (InfoTekjar), vol. 2, no. 1, pp. 1-9, 2017.

[5] H. A. Musril, "Penerapan Open Shortest Path First (OSPF) untuk Menentukan Jalur Terbaik dalam Jaringan,” Jurnal Elektro Telekomunikasi Terapan (JETT), vol. 4, no. 1, pp. 421-431, 2017.

[6] T. Mulyadin, M. Sholeh, and C. Iswahyudi, "Implementasi Routing Open Shortest Path First (OSPF) Melalui Tunnel Open VPN," Jurnal JARKOM, vol. 4, no. 1, pp. 62-70, 2016.

[7] T. D. Purwanto, "Perancangan Jaringan VPN Router Dengan Metode Link State Routing Protocols," Seminar Nasional Inovasi dan Tren (SNIT), pp. A69-A74, 2014.

[8] C. Umam, E. Roza, and Irfan, "Perancangan Jaringan Keamanan Virtual Private Network (VPN) Site to Site," Seminar Nasional TEKNOKA FT UHAMKA, pp. 23-30, 2016.

[9] A. Masykuri, E. Utami, and Sudarmawan, "Implementasi VPN Server dalam Sistem Informasi Apotek (Studi Kasus Integrasi Sistem Informasi Apotek Santi Pontianak), ”Jurnal Ilmiah DASI, vol. 17, no. 2, pp. 7-12, 2016.

[10] Y. Syafitri, "Mengamankan Pengiriman Data Dari Malware Berbasis VPN Menggunakan Router Cisco di Kampus DCC," Jurnal Cendikia, vol. 10, no. 1, pp. 10-14, 2014.

\section{BIOGRAFI PENULIS}

\section{Hari Antoni Musril}

Lahir di Padang, 7 September 1983. Menyelesaikan program S1

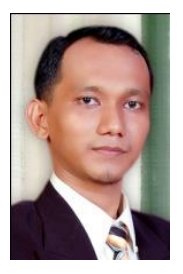
Sarjana Komputer (S.Kom) pada jurusan Sistem Komputer Universitas Putra Indonesia "YPTK" Padang tahun 2007. Menyelesaikan program S2 Magister Komputer (M.Kom) pada Universitas Putra Indonesia “YPTK” Padang tahun 2009. Saat ini sebagai dosen tetap pada program studi Pendidikan Teknik Informatika dan Komputer, yang berada dalam Fakultas Tarbiyah dan Ilmu Keguruan di Institut Agama Islam Negeri (IAIN) Bukittinggi. 